\title{
ANÁLISE DO INVESTIMENTO E PRODUÇÃO EM C\&T NO BRASIL ENTRE 2002 E 2010
}

1-Camila Guimarães Monteiro de Freitas Alves

Mestre em Gestão e Estratégia pela Universidade Federal Rural do Rio de Janeiro (PPGE/UFRRJ-RJ), Brasil. camila_gmf@hotmail.com

http://lattes.cnpq.br/5426171291707066

\section{2-Murilo Alvarenga Oliveira}

Doutor em Administração pela Universidade de São Paulo (USP-SP), Brasil.

Professor do Programa de Pós Graduação em Administração da Universidade Federal Fluminense (UFF), Brasil. malvarenga@vm.uff.br

http://lattes.cnpq.br/1138897474101598

\author{
Diego Maganhotto Coraiola - Editor Geral \\ Editor responsável pela submissão: \\ Emerson Antonio Maccari.
}

Artigo analisado via processo de revisão duplo cego (Double-blind).

Recebido em: 10/04/2013

Aprovado em: 05/05/2014

Última Alteração: 04/02/2014

* Contato Principal: Rua Dr. Antonio Barreiros, 212, Nossa Senhor das Graças, Volta Redonda - RJ, Brasil. CEP: $27215-350$. 


\section{ANÁLISE DO INVESTIMENTO E PRODUÇÃO EM C\&T NO BRASIL ENTRE 2002 E 2010}

\section{RESUMO}

O objetivo do estudo foi analisar a relação entre o esforço público para o progresso da ciência e da tecnologia por meio dos investimentos realizados pelo Conselho Nacional de Desenvolvimento Científico e Tecnológico (CNPq) e a produção técnico-científica do país em termos de publicação de artigos em periódicos e geração de patentes. A base teórica abordou os conceitos sobre ciência, tecnologia e inovação (CT\&l) e o contexto brasileiro de incentivo à CT\&l. A questão de pesquisa trata da relação entre o investimento em ciência e tecnologia, a publicação e a produção técnica no Brasil. O estudo foi de natureza descritiva com tratamento quantitativo por análise de correlação. Os meios de investigação foram por pesquisa bibliográfica e documental. A coleta dos dados consistiu na identificação dos investimentos realizados pelo CNPq descritos em seu balanço nos anos de 2002 a 2010 e a produção técnico-científica neste período. Os resultados apontam a existência da relação entre o investimento em C\&T com a produção técnico-científica. Em relação à publicação, observa-se que esta possui correlação com cinco dos sete itens dos investimentos analisados e baixa correlação com dois itens. No que tange à produção técnica, também há correlação com cinco dos sete itens.

\section{Palavras-Chave}

Investimento em Ciência, Tecnologia e Inovação; produção técnico-científica; contexto brasileiro.

\section{ANALYSIS OF INVESTMENT AND PRODUCTION IN S\&T IN BRAZIL BETWEEN 2002 AND 2010 \\ ABSTRACT}

The objective of the study was to analyze the relationship between the public effort for the advancement of science and technology through investments made by the National Counsel of Technological and Scientific Development $(\mathrm{CNPq})$ and technical-scientific production of the country in terms of publication of papers in journals and patent generation. The theoretical basis discussed the concepts about science, technology and innovation (ST\&I) and the Brazilian context to encourage ST\&I. The research question deals with the relationship between investment in science and technology, publishing and technical production in Brazil. The study was of a descriptive nature with quantitative treatment by correlation analysis. Means of investigation were by literature and documents. The data collecting consisted of identifying the investments made by CNPq described on its balance sheet for the years 2002 to 2010 and the technical-scientific production in this period. The results indicate the existence of the relationship between investment in S\&T with the technical-scientific production. With regard to publication, it is observed that this correlation has five of the seven items of investments analyzed and low correlation with two items. Regarding the technical production, there are also correlated with five of the seven items.

\section{Keywords}

Investment in science, technology and innovation; technical-scientific production; Brazilian context. 


\section{Introdução}

O conhecimento possui um papel fundamental no progresso de um país e uma importância cada vez maior na dinâmica econômica e social, estando o conhecimento relacionado tanto ao capital intangível quanto ao fator de produção. Juntamente com o avançar do conhecimento, as relações entre ciência, tecnologia e inovação tornaram-se determinantes para o desenvolvimento. Segundo Malerba (2002), o conhecimento desempenha um papel central na inovação e na produção.

Schumpeter (2002) foi um dos primeiros autores a enfatizar a importância da inovação no desenvolvimento das empresas e da sociedade, destacando que a capacidade de inovação é um diferencial que possibilita que as organizações tenham valor agregado e maior competitividade. Corroborando este pensamento, Quintella et al (2012) e Pereira e Reinert (2013) afirmam que o conhecimento e a inovação são pontos importantes para o desenvolvimento das sociedades e cada vez mais objeto de estudos e pesquisas em diversas áreas.

Tigre (1998) destaca que a firma passa por diversas transformações, diferenciada pela incorporação de novas tecnologias organizacionais a um ritmo e abrangência sem precedentes na história econômica, além da globalização. Em resposta, as firmas passam a buscar competitividade, combinando novas estratégias, inovações tecnológicas e organizacionais.

A visão que norteia este estudo está baseada no fato de que para evolução é necessário o progresso técnico, sendo este último estabelecido na relação entre o conhecimento e o desenvolvimento científico e tecnológico.

De acordo com Zawislak, Borges, Wegner, Santos and Castro (2008) os investimentos tanto governamentais quanto industriais em tecnologia e inovação influenciam os resultados de desenvolvimento, havendo uma relação direta entre inovação e desenvolvimento.

Com relação ao cenário brasileiro, é ponto comum em documentos de política tecnológica, no Brasil, a indicação de fortalecimento da relação entre empresas e a infraestrutura de tecnologia e inovação, a qual inclui universidades, institutos de pesquisa públicos e privados, centros de formação e treinamento, consultorias, banco de dados, ou seja, possibilitando um maior ajuste entre os vários atores que compõem o sistema local e nacional de inovação (Figueiredo, 2004).

No Brasil, nos últimos anos, tem-se incentivado a concepção de políticas de inovação por parte do governo, por meio de estímulo aos pesquisadores, criação dos núcleos de inovação e a promulgação de leis. Podem-se destacar diversas realizações que aconteceram nas últimas décadas com o amadurecimento científico e tecnológico. O país cresceu a partir da década de 1970, não só no aspecto relacionado ao conhecimento científico como também em desenvolvimento tecnológico, com a difusão e a estruturação de programas de formação de pessoal e de P\&D.

No que tange aos instrumentos, o país criou, nos últimos 10 a 20 anos, um aparato para o apoio à pesquisa e ao desenvolvimento, como, por exemplo, fundos setoriais, lei da informática, lei da inovação, lei do bem e mecanismos de subvenção, que constituem um arsenal, um portfólio de recursos que podem ser mobilizados para o desenvolvimento tecnológico. Diversas são as políticas de inovação e incluem leis, regulamentações, planos, programas, incentivos fiscais e não fiscais, diretos e indiretos, de forma a criar um ambiente favorável tanto por parte dos vários níveis de governos como das empresas.

Este estudo delimitou-se à análise dos investimentos do Brasil em pesquisa e a produção científica em termos de publicação nacional de artigos em bases científicas e geração de patentes (produção técnica). A motivação foi reforçada pela posição do Brasil na produção de ciência. No que tange à publicação de artigos brasileiros em periódicos científicos, ao compará-la ao total mundial, o Brasil possui um percentual de publicação em relação ao mundo, segundo a base Scopus, de 2,2\%.

O objetivo do presente estudo foi analisar a relação entre o esforço público para o progresso da ciência e da tecnologia por meio dos avanços dos investimentos realizados pelo Conselho Nacional de Desenvolvimento Científico e Tecnológico (CNPq) e a produção científica do país.

Nesse contexto brasileiro de publicação de artigos e pedidos de patente, questiona-se: "Existe correlação entre o investimento em ciência e tecnologia e a publicação e a produção técnica?".

Após esta introdução, são apresentados os conceitos sobre ciência, tecnologia e inovação (CT\&l) e o contexto brasileiro de incentivo à CT\&l. A seguir, apresenta-se a metodologia de pesquisa. Na sequência, aborda-se a análise e interpretação dos dados extraídos, finalizando com algumas considerações a respeito dos principais achados.

\section{Fundamentação Teórica}

\subsection{Ciência, Tecnologia e Inovação}

De acordo com Zawislak (1994), a ciência é a decomposição da ação, originando conhecimentos sobre determinado tema. É o logos puro, apresentando o know-why de um fenômeno, gerando conhecimento e servindo de base para o estudo da ação. Para o autor, a tecnologia é a definição do conhecimento gerado de 
forma sistematizada. A tecnologia não deixa de ser técnica, é a técnica que se distancia do empirismo, concebendo procedimentos que nascem de um processo científico antecedente de procura de soluções com base em princípios teóricos previamente definidos. Segundo Tigre (2006), a tecnologia é o conhecimento sobre técnicas. Já para Dosi (1988), a tecnologia é vista como um complexo de conhecimentos práticos e teóricos, englobando tanto equipamentos físicos quanto know-how, métodos, procedimentos e experiências.

O avanço do conhecimento científico relaciona-se ao fato de se empregar a ciência como estoque de conhecimento a ser explorado na resolução de problemas. Neste sentido, a ligação entre ciência e tecnologia possibilita que os avanços da ciência melhorem a resolução de problemas e capacidades de Pesquisa \& Desenvolvimento aplicados, sendo que a ciência desempenha tanto um papel de estoque de conhecimento como um fluxo de conhecimento (Klevorick, Levin, Nelson, \& Winter, 1995).

Por meio do conhecimento também podem surgir inovações. Os primeiros estudos sobre inovação buscavam explicar a relação entre inovação tecnológica e desenvolvimento econômico, focando no desenvolvimento de produtos e processos com aplicação comercial. Com a ampliação do interesse no estudo da inovação, ampliou-se seu escopo, passando a englobar também inovações sociais, inovações em serviços e inovações no setor público (Brandão, \& Bruno-Faria, 2013).

Segundo Etzkowitz (2009, p. 5), a inovação vem ganhando “um significado ainda mais amplo nas sociedades cada vez mais fundamentadas no conhecimento." De acordo com o autor, antigamente, a inovação era vista apenas como o desenvolvimento de novos produtos e, hoje, também inclui a criação de arranjos organizacionais que facilitem o processo de inovação.

Para Cooke (2003), a inovação é um fator importante para a competitividade, além de ser um processo de interação social. Já Teece (2002, p. 422), no que diz respeito à inovação, afirma que o aspecto mais importante seria a capacidade de "criar, transferir, montar, integrar, proteger e explorar ativos de conhecimento", ou seja, a capacidade de gerir seu capital intelectual.

Conforme a Organização para Cooperação e Desenvolvimento Econômico (OCDE) (2005), inovação é a implementação de um produto (bem ou serviço) novo ou significativamente melhorado, ou um processo, ou um novo método de marketing, ou um novo método organizacional nas práticas de negócios, na organização do local de trabalho ou nas relações externas.

Neste sentido, observa-se o seguinte conceito de inovação no Manual de Oslo da OCDE (1997, p.131):

introdução de produtos ou processos tecnologicamente novos e melhorias significativas naqueles já existentes. Considera-se que uma inovação tecnológica de produto ou processo tenha sido implementada se tiver sido introduzida no mercado (inovação de produto) ou utilizada no processo de produção (inovação de processo). As inovações tecnológicas de produto ou processo envolvem uma série de atividades científicas, tecnológicas, organizacionais, financeiras ou comerciais.

A literatura também aborda a inovação em gestão, a qual engloba a geração e implementação de práticas gerenciais, processos, estruturas ou técnicas que são novas para o estado da arte e que maximizem os objetivos organizacionais (Birkinshaw, Hamel, \& Mol, 2008). Segundo Hicks (1932), as inovações são norteadas para que os fatores sejam economizados, principalmente no que se refere ao trabalho, com o intuito de minimizar o declínio da lucratividade.

De acordo com Nemet (2009), as fontes introdutoras das inovações são: necessidades explícitas dos consumidores (demand-pull) ou oportunidades originadas a partir dos progressos da ciência e da tecnologia (technology push). Segundo Mowery and Rosenberg (1979), as inovações podem ser explicadas tanto pela oferta tecnológica quanto pela demanda do mercado, sendo que esses fatores interagem e existem concomitantemente.

O aprendizado com base no avanço da ciência deriva do monitoramento dos resultados de pesquisas realizadas em universidades e centros tecnológicos, destacando-se que algumas empresas possuem forte interação com esses centros de geração de conhecimento (Tigre, 2006). A pesquisa acadêmica tem sido cada vez mais reconhecida como necessária para a criação e disseminação do conhecimento, seja em sistemas nacionais de inovação (Lundvall, 1992) ou sistemas de inovação locais e regionais (Asheim, \& Isaksen, 2002).

O Sistema Nacional de Inovação pode ser definido como uma rede de instituições públicas e privadas que interagem visando promover o desenvolvimento científico e tecnológico de um país. Inclui empresas, inclusive industriais e de consultoria, universidades, entidades de ensino, institutos de pesquisa, agências governamentais de fomento, agências reguladoras e associações empresariais, em um esforço de geração, importação, modificação, adaptação e difusão de inovações (Nelson, 1993).

Nas modernas sociedades, a complexidade tecnológica alcançou estágios nas quais é indispensável o investimento em inovação, sendo o processo de inovação subdividido em etapas, conforme abordado por Zawislak (1994), as quais são: pesquisa fundamental, pesquisa aplicada, P\&D industrial, inovação e produção.

A pesquisa fundamental refere-se a um trabalho experimental ou teórico, cujo objetivo é obter novos conhecimentos sobre os fundamentos dos fenômenos, sem preocupar-se com uma aplicação imediata, visto que visa o acúmulo de informações cientifico-tecnológicas e o avanço da fronteira em todos os campos do conhecimento. 
A pesquisa aplicada também está relacionada à investigação original realizada com o intuito de produzir novos conhecimentos. Entretanto, esta possui um objetivo característico, evoluindo do geral para o específico, da produção para a aplicação, partindo das universidades até chegar às empresas.

O desenvolvimento experimental ou P\&D tem como objetivo a solução de um problema real e imediato, buscando produzir novos materiais, produtos ou dispositivos, instalar novos processos, sistemas ou serviços, ou melhorar produtos e processos, com base no conhecimento científico existente e acumulado com a pesquisa fundamental e aplicada.

Se de um lado temos a inovação técnica, baseada em conhecimentos empíricos adquiridos na prática e com a experiência, do outro, temos um processo de inovação tecnológica, baseada no conhecimento científico, sendo que a partir deste segundo processo é que a ciência e a tecnologia assumem o seu status de motor do desenvolvimento, representada pelo sistema tecno-científico (OCDE, 2002).

Percorridas as etapas de desenvolvimento, o processo de inovação será efetivado pela produção e/ou comercialização dos produtos ou, ainda, pela utilização dos processos desenvolvidos, sendo que as soluções implementadas são importantes contribuições à melhoria de processos e produtos.

\subsection{Contexto Brasileiro De Incentivo À CT\&l}

De acordo com Schumpeter (1961), o impulso que mantém o motor do capitalismo em movimento não provém de fenômenos naturais ou sociais, mas dos novos bens, novos métodos, novos mercados e novas formas de organização industrial que a empresa capitalista cria e destrói. Schumpeter, assim como Marx, destaca que o motor do desenvolvimento é estabelecido pela mudança tecnológica, revolucionando a estrutura econômica por um processo de criação destruidora.

$\mathrm{Na}$ era do conhecimento, tem se tornado cada vez mais importante a informação, aliada à ciência, à tecnologia, ao conhecimento e à inovação tecnológica, os quais influenciam o desenvolvimento. O desenvolvimento científico e tecnológico possibilita transformações mais intensas na sociedade, exigindo que esta esteja preparada para lidar com os desafios cotidianos (Zawislak, 1994).

A inovação é primordial para o desenvolvimento de um país no mundo globalizado, onde a concorrência capitalista se encontra cada vez mais forte, sendo que esta concorrência acelerou a disseminação de tecnologias, facilitou o avanço do conhecimento e modificou a relação entre ciência, tecnologia e inovação (Pacheco, 2010).

Neste contexto, universidades, centros de pesquisa e organizações precisam direcionar seus esforços financeiros, de pessoal e de criação de um ambiente de inovação visando o desenvolvimento de ciência, tecnologia e inovação e, consequentemente, segundo Zawislak et al (2008), o desenvolvimento tecnológico do país.

De acordo com Figueiredo (2004), a política tecnológica ingressou formalmente na agenda de discussão e ação governamental, no Brasil, no final dos anos 1960, a partir da elaboração do I Plano Nacional de Desenvolvimento (PND, 1972/74) e do Plano Básico de Desenvolvimento Científico e Tecnológico (PBDCT, 1973/74), seguidos do II e do III PBDCTs.

Segundo Pacheco (2010), no decorrer dos anos 70, no Brasil, teve início o desenvolvimento de um sistema de Ciência e Tecnologia que previa a substituição de importações de insumos básicos e bens de capital visando a autossuficiência industrial e a autonomia tecnológica. Já nos anos 80 e 90, ocorreu a globalização, que exigiu dos países um novo modelo de Ciência e Tecnologia devido ao crescimento da competitividade. Nesse período, a economia brasileira ficou estagnada por ainda manter o antigo modelo de substituição de importação ao invés de se integrar aos demais países. Entretanto, em meados da década de 90, o Brasil buscou um novo modelo de C\&T que possibilitou maior integração mundial.

Nos últimos anos, o governo federal instituiu ferramentas que possibilitaram, após a crise dos anos 1990, a retomada de seu papel na promoção da expansão do Sistema Nacional de CT\&l, contribuindo de forma mais decisiva para o desenvolvimento nacional. Além disso, a sociedade brasileira despertou para o valor estratégico da ciência e da tecnologia, observado na nova postura de empresas e de setores em relação aos investimentos crescentes em inovação tecnológica, na disposição de pesquisadores e grupos universitários para interagir com empresas e criar condições à geração de novas empresas inovadoras e na inserção das questões de CT\&l na agenda de prioridades do Congresso Nacional (Rezende, 2011).

Observando-se o contexto do sistema nacional de inovação, no Brasil, conforme Garnica e Jugend (2009), destaca-se que as instituições públicas de desenvolvimento científico e tecnológico estiveram desorientadas durante muito tempo com relação aos procedimentos necessários para a gestão do conhecimento advindos delas próprias e obtenção de recursos financeiros para a realização de pesquisas, além de não darem importância para a colaboração interinstitucional na promoção da inovação.

Entretanto, o Ministério de Ciência, Tecnologia e Inovação vem se orientando para a implementação de uma Política de CT\&l, de forma a constituir um planejamento que envolva os diversos atores institucionais. Segundo Salles-Filho e Bonacelli (2007), o desenvolvimento brasileiro, nos últimos dois séculos, deve muito ao trabalho, produtos e serviços criados e difundidos por organizações públicas de pesquisa, tanto de âmbito 
federal quanto estadual, destacando que essas organizações são essenciais para o desenvolvimento e não podem estar à margem da formulação e implementação das políticas de desenvolvimento científico, tecnológico, industrial, agrícola, de saúde e ambiental.

No contexto atual, a busca pelo aumento da competitividade levou governos de países a criarem políticas de incentivo à inovação, sendo que a combinação de políticas governamentais e estratégias empresariais cria um ambiente propício à geração de inovações. Nesse cenário, políticas de incentivo à inovação vêm surgindo no Brasil. Tanto o governo Federal, por meio de órgãos e agências como a Financiadora de Estudos e Projeto FINEP, Banco Nacional de Desenvolvimento Econômico e Social - BNDES, Ministério de Ciência, Tecnologia e Inovação - MCTI, Coordenação de Aperfeiçoamento de Pessoal de Nível Superior - CAPES e Conselho Nacional de Desenvolvimento Científico e Tecnológico - CNPq, como os governos Estaduais aumentaram seus investimentos em inovação (Pacheco, 2010).

Houve também, na última década, modificações no marco regulatório e nos instrumentos de apoio à CT\&l, visando aproximar os esforços públicos das iniciativas de desenvolvimento tecnológico das empresas. Voltando-se para o plano institucional, a constituição de fóruns de competitividade, a partir do ano 2000 , foi uma questão importante para construir uma política industrial que integra órgãos públicos e a iniciativa privada (Arcuri, 2010).

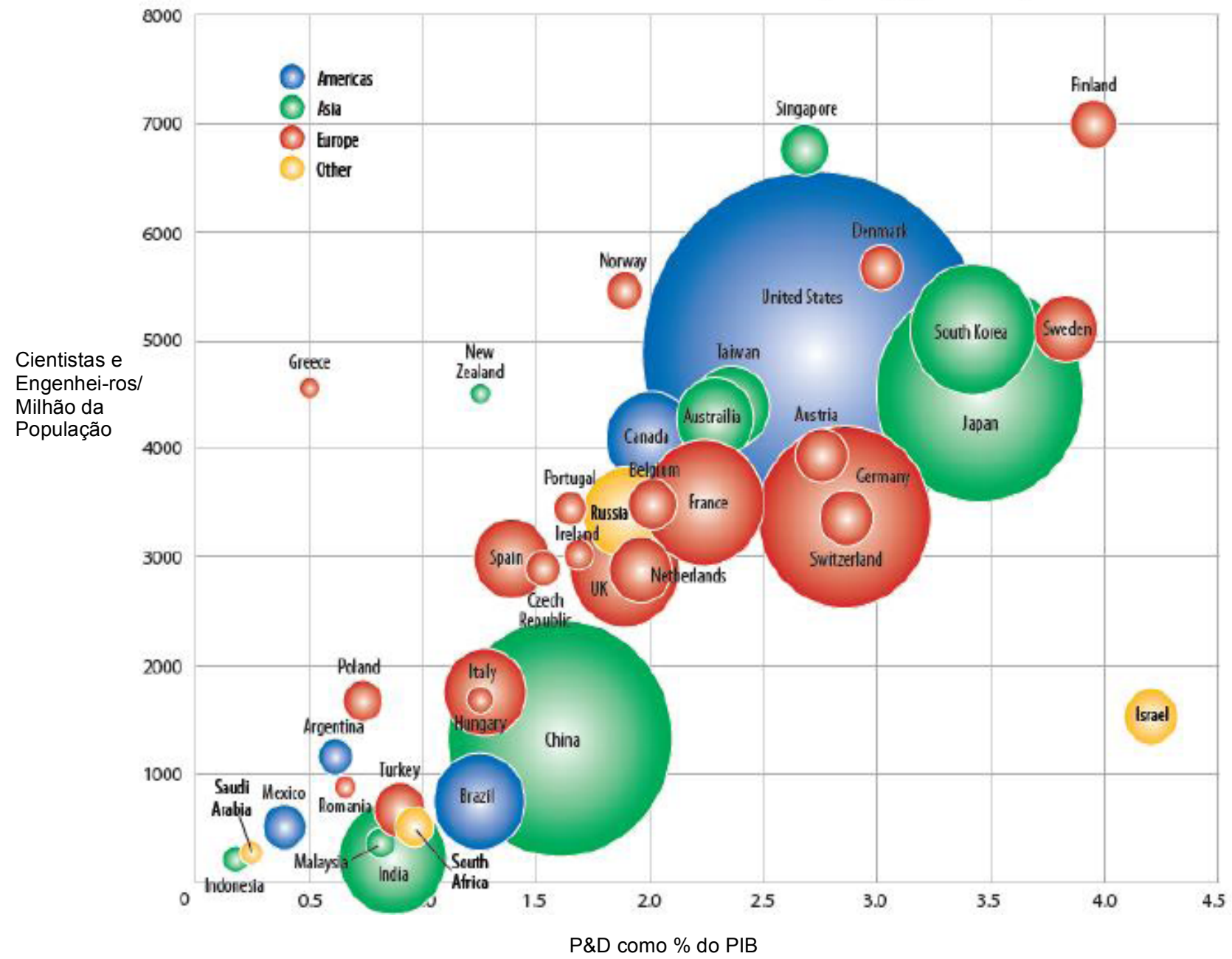

Figura 1: Gastos Mundiais em P\&D em 2011

Nota Fonte: Battelle (2012). Global R\&D Funding Forecast. R\&D Magazine. Recuperado em 5 abril, 2013, de http://battelle.org/docs/defaultdocument-library/2012_global_forecast.pdfComo marcos da política de CT\&l que vem sendo desenvolvida pelo governo brasileiro, destaca-se o estabelecimento do marco legal, com a criação das Leis da Inovação e do Bem e a definição de receitas da União para promover atividades de PD\&I (fundos setoriais).

A Lei no 10.973 (2004), chamada Lei da Inovação, visa contribuir para o delineamento de um contexto favorável ao desenvolvimento científico, tecnológico e de incentivo à inovação. Em seu Artigo $1^{\circ}$, a lei estabelece medidas de incentivo à inovação e à pesquisa científica e tecnológica, com vistas à capacitação da mão-de-obra e ao alcance da autonomia tecnológica e ao desenvolvimento industrial do país. Os pressupostos para a criação dessa lei foram o reconhecimento da inovação como um dos maiores promovedores do 
desenvolvimento do país e a recuperação do parque tecnológico nacional, que está defasado se comparado ao de outros países de mesma importância mundial (Pacheco, 2010). Essa lei estabelece diretrizes para o fomento de pesquisas científicas e tecnológicas, regras para a proteção da propriedade intelectual, além do arcabouço legal para a realização de integrações entre universidades, empresas e governo visando o desenvolvimento da inovação.

Outra Lei criada pelo governo brasileiro para incentivar a inovação é a Lei no 11.196 (2005), denominada Lei do Bem, que prevê a concessão de incentivos fiscais às empresas que realizam pesquisa e desenvolvimento para a inovação, seja em produto, processo ou serviço.

Além do marco legal, segundo Figueiredo (2004), ao longo dos últimos anos, vários mecanismos de apoio financeiro têm sido implementados no Brasil para a formação e consolidação de infraestruturas de tecnologia e inovação.

$\mathrm{Na}$ figura 1, segundo dados do portal Battelle.org (http://battelle.org/docs/default-documentlibrary/2012_global_forecast.pdf, recuperado em 5 abril, 2013), pode-se analisar os gastos mundiais em P\&D e compará-los como porcentagem do PIB (Produto Interno Bruto). Observa-se que os maiores investimentos em P\&D no ano de 2011 foram realizados pelos Estados Unidos, em 1ㅇ lugar, e pela China, em 2ㅇ lugar. Com relação aos países da América Latina, o Brasil é o que realizou os maiores investimentos. No que diz respeito aos investimentos em P\&D como porcentagem do PIB, os maiores valores encontram-se em Israel e na Finlândia. Como porcentagem do PIB, no Brasil, os investimentos em P\&D encontram-se em torno de $1,25 \%$ do PIB.

A partir do governo do presidente Luiz Inácio Lula da Silva, compreendido entre os anos 2003 e 2010 , destaca-se a ampliação da universidade pública, com a criação de 14 novas universidades federais e mais 100 campi. Além disso, tem crescido o apoio financeiro às atividades de pesquisa voltadas para o desenvolvimento da ciência, tecnologia e inovação por parte de instituições públicas como a Finep, a CAPES, o CNPq e as Fundações de Amparo à Pesquisa dos Estados (FAPs), com o aumento do orçamento do MCTI, entre 2000 e 2010, de R\$1,19 bilhões para R \$ 6,3 bilhões (Lemos, \& De Nigre, 2010).

$\mathrm{Na}$ Tabela 1 , conforme os dados disponibilizados pelo MCTI, (http://www.mct.gov.br/index.php/content/view/9058/Brasil_Dispendio_nacional_em_ciencia_e_tecnologia_C_T_s up_1_sup_.html, recuperado em 6 outubro, 2012) pode-se ōbservar o aumento do dispêndiō náacional em ciência e técnologia entre 2000 e 2010, no qual o investimento público passou de R\$ 8,6 milhões para R\$32,8 milhões. Já os investimentos empresariais neste mesmo período passaram de $R \$ 6,6$ milhões para $R \$ 28,1$ milhões.

Tabela 1

Dispêndio do Brasil em Ciência e Tecnologia (C\&T), 2000-2010

\begin{tabular}{|c|c|c|c|c|c|c|c|c|c|c|c|}
\hline \multirow{3}{*}{ Ano } & \multirow{3}{*}{$\begin{array}{c}\text { PIB } \\
\text { (milhões R\$) }\end{array}$} & \multicolumn{7}{|c|}{$\begin{array}{c}\text { Dispêndios em C\&T } \\
\text { (em milhões de R\$) }\end{array}$} & \multicolumn{3}{|c|}{$\begin{array}{c}\text { \% em relação } \\
\text { ao PIB }\end{array}$} \\
\hline & & \multirow[b]{2}{*}{ Federais } & \multirow{2}{*}{$\begin{array}{l}\text { Públicos } \\
\text { Estaduais }\end{array}$} & \multirow[b]{2}{*}{ Total } & \multicolumn{3}{|c|}{ Empresariais } & \multirow[b]{2}{*}{ Total } & \multirow[b]{2}{*}{ Público } & \multirow[b]{2}{*}{ Privado } & \multirow[b]{2}{*}{ Total } \\
\hline & & & & & $\begin{array}{c}\text { Empresas } \\
\text { privadas e } \\
\text { estatais }\end{array}$ & Outras & Total & & & & \\
\hline 2000 & 1.179 .482 & 5.795 & 2.854 & 8.649 & 5.455 & 1.183 & 6.638 & 15.288 & 0,73 & 0,56 & 1,30 \\
\hline 2001 & 1.302 .136 & 6.266 & 3.287 & 9.553 & 6.058 & 1.650 & 7.709 & 17.262 & 0,73 & 0,59 & 1,33 \\
\hline 2002 & 1.477 .822 & 6.522 & 3.473 & 9.995 & 6.688 & 2.593 & 9.281 & 19.277 & 0,68 & 0,63 & 1,30 \\
\hline 2003 & 1.699 .948 & 7.392 & 3.705 & 11.098 & 7.335 & 2.960 & 10.295 & 21.393 & 0,65 & 0,61 & 1,26 \\
\hline 2004 & 1.941 .498 & 8.688 & 3.900 & 12.588 & 7.941 & 3.510 & 11.451 & 24.040 & 0,65 & 0,59 & 1,24 \\
\hline 2005 & 2.147 .239 & 9.570 & 4.027 & 13.597 & 10.216 & 3.463 & 13.679 & 27.277 & 0,63 & 0,64 & 1,27 \\
\hline 2006 & 2.369 .484 & 11.476 & 4.282 & 15.758 & 11.783 & 3.076 & 14.859 & 30.618 & 0,67 & 0,63 & 1,29 \\
\hline 2007 & 2.661 .344 & 14.083 & 5.687 & 19.770 & 13.734 & 3.692 & 17.426 & 37.197 & 0,74 & 0,65 & 1,40 \\
\hline 2008 & 3.032 .203 & 15.974 & 7.138 & 23.112 & 15.827 & 5.158 & 20.985 & 44.098 & 0,76 & 0,69 & 1,45 \\
\hline 2009 & 3.239 .404 & 18.475 & 8.424 & 26.900 & 17.987 & 7.001 & 24.989 & 51.889 & 0,83 & 0,77 & 1,60 \\
\hline 2010 & 3.770 .084 & 22.577 & 10.201 & 32.778 & 20.407 & 7.713 & 28.120 & 60.899 & 0,87 & 0,75 & 1,62 \\
\hline
\end{tabular}

Nota. Fonte: Ministério da Ciência, Tecnologia e Inovação do Brasil. (2012). Brasil: Dispêndio nacional em ciência e tecnologia (C\&T), 20002010. Recuperado em 6 outubro, 2012, de

http://www.mct.gov.br/index.php/content/view/9058/Brasil_Dispendio_nacional_em_ciencia_e_tecnologia_C_T_sup_1_sup_.html.

Ainda neste contexto de ciência e tecnologia, voltando-se para a relação dos países com o maior número de publicações, de acordo com dados do Scimago Journal \& Country Rank, 
(http://www.scimagojr.com./countryrank.php?area=0\&category=0\&region=all\&year $=2011 \&$ order $=i t \& \mathrm{~min}=0 \& \mathrm{~m}$ in type=it, recuperado em 13 abril, 2013), conforme a Tabela 2, observa-se os países com maior participação pércentual em relação ao total mundial de artigos publicados em periódicos científicos indexados pela Scopus em 2011. O Brasil assume a 13a posição, com uma participação de $2 \%$. Os 20 países que mais publicaram artigos na Scopus acumulam $82,1 \%$ da publicação mundial.

Já no que tange aos pedidos de patentes depositados no escritório de marcas e patentes dos Estados Unidos da América (United State Patent and Trademark Office - USPTO), (http://www.uspto.gov/web/offices/ac/ido/oeip/taf/appl_yr.htm, recuperado em 3 abril, 2013), em 2011, o Brasil realizou 586 pedidos de patentes, bem abaixo dos nove primeiros colocados, que são Estados Unidos da América, Japão, Alemanha, Coréia do Sul, Taiwan, Canadá, Reino Unido, França e China, que neste mesmo período realizaram mais de 10 mil pedidos de patente cada. O Brasil encontra-se na 17 ạ posição dos 20 países do ranking.

Com relação à posição da economia brasileira, segundo o Fundo Monetário Internacional (International Monetary Fund) (http://www.imf.org/external/pubs/ft/weo/2012/02/weodata/download.aspx, recuperado em 13 abril, 2013), o Brasil está na 7ạ colocação em relação à economia mundial, de acordo com o FMl.

Observa-se que existe uma lacuna entre a posição econômica do Brasil e sua posição na publicação de artigos e pedidos de patente. Enquanto no primeiro caso o país encontra-se na 7ạ posição, nos demais nas 13ạ e 17 ạ posições, respectivamente.

Tabela 2

Panorama dos países quanto a Publicação de artigos, pedidos de patente e posição econômica

\begin{tabular}{|c|c|c|c|c|c|c|c|}
\hline País & $\begin{array}{l}\text { Colocação na } \\
\text { publicação de } \\
\text { artigo }\end{array}$ & $\begin{array}{l}\text { Publicação de } \\
\text { Artigos } \\
2011^{\mathrm{a}}\end{array}$ & $\begin{array}{l}\text { Participação na } \\
\text { publicação de } \\
\text { artigo \% }\end{array}$ & $\begin{array}{c}\text { Coloca- } \\
\text { ção no } \\
\text { número de } \\
\text { pedidos } \\
\text { de patente }\end{array}$ & $\begin{array}{l}\text { Pedidos } \\
\text { de Patente } \\
2011^{\mathrm{b}}\end{array}$ & $\begin{array}{l}\text { Participa- } \\
\text { ção nos } \\
\text { Pedidos de } \\
\text { Patente \% }\end{array}$ & $\begin{array}{l}\text { Colocação na } \\
\text { economia } \\
\text { mundial }^{c}\end{array}$ \\
\hline $\begin{array}{l}\text { Estados } \\
\text { Unidos da } \\
\text { América }\end{array}$ & 1 & 519.573 & $19,9 \%$ & 1 & 247.750 & $49,20 \%$ & 1 \\
\hline China & 2 & 373.756 & $14,3 \%$ & 9 & 10.545 & $2,09 \%$ & 2 \\
\hline Reino Unido & 3 & 145.899 & $5,6 \%$ & 7 & 11.279 & $2,24 \%$ & 6 \\
\hline Alemanha & 4 & 137.519 & $5,3 \%$ & 3 & 27.935 & $5,55 \%$ & 4 \\
\hline Japão & 5 & 115.416 & $4,4 \%$ & 2 & 85.184 & $16,92 \%$ & 3 \\
\hline França & 6 & 97.343 & $3,7 \%$ & 8 & 10.563 & $2,10 \%$ & 5 \\
\hline India & 7 & 88.437 & $3,4 \%$ & 10 & 4.548 & $0,90 \%$ & 11 \\
\hline Canadá & 8 & 80.679 & $3,1 \%$ & 6 & 11.975 & $2,38 \%$ & 10 \\
\hline Itália & 9 & 77.838 & $3,0 \%$ & 12 & 4.282 & $0,85 \%$ & 8 \\
\hline Espanha & 10 & 71.155 & $2,7 \%$ & 15 & 1.501 & $0,30 \%$ & 13 \\
\hline Austrália & 11 & 63.149 & $2,4 \%$ & 14 & 3.767 & $0,75 \%$ & 12 \\
\hline $\begin{array}{c}\text { Coréia do } \\
\text { Sul }\end{array}$ & 12 & 60.846 & $2,3 \%$ & 4 & 27.289 & $5,42 \%$ & 14 \\
\hline Brasil & 13 & 49.664 & $2,0 \%$ & 17 & 586 & $0,12 \%$ & 7 \\
\hline Holanda & 14 & 45.689 & $1,8 \%$ & 11 & 4.418 & $0,88 \%$ & 17 \\
\hline Taiwan & 15 & 40.234 & $1,5 \%$ & 5 & 19.633 & $3,90 \%$ & 26 \\
\hline Rússia & 16 & 39.005 & $1,5 \%$ & 16 & 719 & $0,14 \%$ & 9 \\
\hline Irã & 17 & 36.803 & $1,4 \%$ & 20 & 80 & $0,02 \%$ & 25 \\
\hline Suíça & 18 & 33.272 & $1,3 \%$ & 13 & 4.086 & $0,81 \%$ & 19 \\
\hline Turquia & 19 & 32.609 & $1,3 \%$ & 19 & 184 & $0,04 \%$ & 18 \\
\hline Polônia & 20 & 29.143 & $1,1 \%$ & 18 & 197 & $0,04 \%$ & 22 \\
\hline Mundo & & 2.607 .945 & $82,1 \%$ & & 503.582 & $94,63 \%$ & \\
\hline
\end{tabular}

Nota. Fonte: ${ }^{a}$ Scimago Journal \& Country Rank. (2012). Country Rankings. Recuperado em 13 abril, 2013, de http://www.scimagojr.com./countryrank.php?area=0\&category=0\&region=all\&year=2011\&order=it\&min=0\&min_type=it. ${ }^{b}$ United States Patent and Trademark Office. Number of Utility Patent Applications Filed in the United States, By Country of Origin, Calendar Years 1965 to Present.

Recuperado em 3 abril, 2013, de http://www.uspto.gov/web/offices/ac/ido/oeip/taf/appl_yr.htm.. 'International Monetary Fund. (2012). World Economic Outlook database. Recuperado em 13 abril, 2013, de http://www.imf.org/external/pubs/ft/weo/2012/02/weodata/download.aspx. 
Com relação à publicação, conforme analisado na Tabela 3, do número de artigos brasileiros em relação ao total mundial de artigos publicados em periódicos científicos indexados pela Thomson/ISI e pela Scopus, disponibilizado na página de indicadores do Ministério da Ciência, Tecnologia e Inovação (MCTI) (http://www.mct.gov.br/index.php/content/view/5710.html, recuperado em 28 dezembro, 2012), observa-se que, em 2009, na Thomson/ISI, o percentual de publicação do Brasil em relação ao mundo foi de 2,69\%. Já na base Scopus, em 2011, esse percentual foi de $2,2 \%$.

Tabela 3

Número de artigos brasileiros, da América Latina e do mundo publicados em periódicos científicos indexados pela Thomson/ISI e Scopus, 2000-2011

\begin{tabular}{|c|c|c|c|c|c|c|c|c|c|c|}
\hline \multirow[b]{2}{*}{ Ano } & \multicolumn{5}{|c|}{ Thomson/ISI } & \multicolumn{5}{|c|}{ Scopus } \\
\hline & Brasil & $\begin{array}{c}\text { América } \\
\text { Latina }\end{array}$ & Mundo & $\begin{array}{c}\text { Brasil / } \\
\text { América } \\
\text { Latina } \\
(\%)\end{array}$ & $\begin{array}{c}\text { Brasil I } \\
\text { Mundo } \\
(\%)\end{array}$ & Brasil & $\begin{array}{l}\text { América } \\
\text { Latina }\end{array}$ & Mundo & $\begin{array}{c}\text { Brasil / } \\
\text { América } \\
\text { Latina } \\
(\%)\end{array}$ & $\begin{array}{c}\text { Brasil I } \\
\text { Mundo } \\
(\%)\end{array}$ \\
\hline 2000 & 10.521 & 24.529 & 777.827 & 42,89 & 1,35 & 12.975 & 29.965 & 1.125 .209 & 43,3 & 1,1 \\
\hline 2001 & 11.581 & 26.478 & 796.862 & 43,74 & 1,45 & 13.649 & 31.108 & 1.177 .198 & 43,9 & 1,2 \\
\hline 2002 & 12.929 & 28.620 & 797.668 & 45,17 & 1,62 & 15.763 & 34.647 & 1.218 .979 & 45,5 & 1,3 \\
\hline 2003 & 14.288 & 31.591 & 875.756 & 45,23 & 1,63 & 17.610 & 38.732 & 1.293 .886 & 45,5 & 1,4 \\
\hline 2004 & 14.995 & 31.655 & 854.703 & 47,37 & 1,75 & 19.554 & 41.285 & 1.436 .379 & 47,4 & 1,4 \\
\hline 2005 & 17.714 & 37.250 & 982.533 & 47,55 & 1,80 & 21.858 & 46.252 & 1.571 .349 & 47,3 & 1,4 \\
\hline 2006 & 19.294 & 38.743 & 983.424 & 49,8 & 1,96 & 27.382 & 54.870 & 1.660 .422 & 49,9 & 1,6 \\
\hline 2007 & 19.510 & 39.367 & 981.932 & 49,56 & 1,99 & 30.040 & 59.290 & 1.748 .024 & 50,7 & 1,7 \\
\hline 2008 & 30.422 & 55.757 & 1.158 .057 & 54,56 & 2,63 & 34.582 & 67.728 & 1.811 .003 & 51,1 & 1,9 \\
\hline 2009 & 32.100 & 58.985 & 1.191 .707 & 54,42 & 2,69 & 39.881 & 75.798 & 1.885 .858 & 52,6 & 2,1 \\
\hline 2010 & $\ldots$ & $\ldots$ & $\ldots$ & $\ldots$ & $\ldots$ & 43.169 & 80.895 & 1.941 .597 & 53,4 & 2,2 \\
\hline 2011 & $\ldots$ & $\ldots$ & $\ldots$ & $\ldots$ & $\ldots$ & 48.515 & 88.787 & 2.026 .258 & 54,6 & 2,2 \\
\hline
\end{tabular}

Nota Fonte: Ministério da Ciência, Tecnologia e Inovação do Brasil. (2012). Número de artigos brasileiros, da América Latina e do mundo publicados em periódicos científicos indexados pela Thomson/ISI e Scopus, 1996-2011. Recuperado em 28 dezembro, 2012 , de http://www.mct.gov.br/index.php/content/view/5710.html.

\section{Procedimentos Metodológicos}

Este trabalho foi de natureza descritiva e, de acordo com Vergara (2000), uma pesquisa descritiva expõe características de determinada população ou de determinado fenômeno, além de também possibilitar estabelecer correlações entre variáveis e definir sua natureza. O fenômeno observado refere-se ao contexto brasileiro de C\&T, os indicadores de C\&T.

No que tange ao corte realizado, este foi seccional com perspectiva longitudinal, no qual, segundo Vieira (2004), a coleta de dados é feita em um momento no tempo, mas resgata dados de outros períodos passados, os quais são utilizados para explicar a configuração do fenômeno.

A pesquisa adotou a abordagem quantitativa, segundo a qual a natureza é uma realidade objetiva, formada de fenômenos em relações causais (Alencar, 2004), por análise de correlação, a qual mede o grau da correlação e a direção dessa correlação, se positiva ou negativa, entre duas variáveis.

Devido o estudo ter por objetivo a análise da relação entre o esforço público para o progresso da C\&T e a produção científica do país, optou-se pela análise de correlação visto que, em estudos que envolvem duas ou mais variáveis, é comum o interesse em conhecer o relacionamento entre as mesmas, sendo o coeficiente de correlação a medida que mostra o grau de relacionamento entre duas variáveis.

Com o intuito de entender a relação entre o esforço púbico em C\&T e a produção científica, cabe destacar que, quanto à escolha das variáveis, os indicadores de ciência e tecnologia existentes no mundo e nos países latino-americanos baseiam-se, normalmente, nas metodologias da Família Frascati organizadas pela Organização para a Cooperação e o Desenvolvimento Econômico (OCDE), os quais se encontram consagrados e são referências em pesquisas que buscam mensurar a CT\&l. Neste sentido, Godinho (2007) elenca como indicadores de C\&T os recursos financeiros relacionados à P\&D, as publicações científicas e as patentes.

Na tabela 4 observam-se as variáveis utilizadas em trabalhos anteriores que serviram como base para a seleção das variáveis na realização deste estudo, as quais foram investimento em C\&T, publicação e patente. 
Tabela 4

Variáveis utilizadas em trabalhos anteriores

\begin{tabular}{cl}
\hline Variável & \multicolumn{1}{c}{ Referência } \\
\hline & Albuquerque (1996), Manual de Bogotá (2001), Manual de Frascati (2002), Godin \\
& (2004), Godinho (2007), Rocha e Ferreira (2004), Arundel (2006), Manual de \\
Santiago (2007), MCTI (2011), Eurostat (Gabinete de Estatísticas da União \\
Europeia).
\end{tabular}
Europeia).

Patente

Albuquerque (1996), Rocha e Ferreira (2004), Arundel (2006), Manual de Santiago (2007), Manual de patentes (2009), Marins e Zawislak (2010), Querido, Lage and Vasconcellos (2011), MCTI (2011), Eurostat (Gabinete de Estatísticas da União Europeia), Godin (2004), Godinho (2007).

Produção Científica

Albuquerque (1996), Ruas (2003), Godin (2004), Rocha e Ferreira (2004), Arundel (2006), Manual de Santiago (2007), MCTI (2011), Godinho (2007).

Nota Fonte: Elaborado pelos autores

Quanto aos meios de investigação, utilizou-se a pesquisa bibliográfica, na qual os dados são coletados por meio de livros, periódicos, dissertações e na internet com dados relacionados ao assunto; e documental, na qual foram levantados os incentivos do governo à ciência e tecnologia por meio do CNPq e dos balanços do MCTI.

O desenvolvimento deste estudo consistiu na coleta de dados, apreciação dos mesmos e análise de correlação. A partir da identificação da questão de pesquisa - existe correlação entre o investimento em ciência e tecnologia e a publicação e a produção técnica? - prosseguiu-se com a etapa de seleção das fontes de informação. A etapa de coleta dos dados consistiu na identificação dos investimentos financeiros realizados pelo CNPq descritos em seu balanço nos anos de 2002 a 2010, disponibilizado no sítio oficial da instituição na internet, visto que esta é uma das formas de transparência que as instituições públicas devem cumprir, destacando-se cinco programas cujos investimentos estão diretamente relacionados à $C \& T$. Os demais programas foram agrupados na variável Outras ações.

Com relação aos dados relativos à publicação e à produção técnica, estes foram obtidos por meio do sítio oficial do Ministério da Ciência, Tecnologia e Inovação, englobando os artigos indexados pela Scopus e considerando-se os softwares com registro ou patente e produtos tecnológicos com registro ou patente, nos anos de 2002 a 2010. Com base nestes dados, realizou-se a análise de correlação.

\section{Apresentação e Análise dos Dados}

A partir do orçamento do CNPq, destacaram-se os programas e ações diretamente relacionados à ciência e tecnologia e a difusão do conhecimento. Neste sentido, foram considerados os investimentos realizados por meio de cinco programas/ações, os quais são: Formação e Capacitação de Recursos Humanos para CT\&l; Promoção da Pesquisa e do Desenvolvimento Científico e Tecnológico; CT\&l para Política Industrial, Tecnológica e de Comércio Exterior - PITCE; Gestão da Política de Ciência, Tecnologia e Inovação e Ciência, Tecnologia \& Inovação Aplicada aos Recursos Naturais. Os demais programas, dentre os quais estão PROANTAR, Programa Nacional de Atividades Espaciais - PNAE, Recursos do Mar, Inclusão Digital, Desenvolvimento da Nanociência e da Nanotecnologia, Competitividade das Cadeias Produtivas/Design, Desenvolvimento da Agroenergia, entre outros, foram agrupados em Outras ações, pois em seu escopo não estavam associados à geração combinada de publicação e patentes, conforme observado na Tabela 5.

Com base nos dados do relatório de gestão do CNPq, observa-se que os programas destacados envolvem várias ações. Estas ações foram descritas a seuir.

O programa de Capacitação de Recursos Humanos para Ciência, Tecnologia e Inovação é responsável pela execução de quatro ações, que envolvem a concessão de bolsas, em diversas modalidades, dentre as quais bolsas de estímulo à pesquisa, de formação e qualificação de pesquisadores, de iniciação científica, de desenvolvimento tecnológico empresarial, além de sistemas de gestão, acompanhamento e avaliação da capacitação de recursos humanos. O objetivo deste programa é formar e capacitar recursos humanos de forma a ampliar e consolidar a base de pesquisa técnico-científica no país. Seu público-alvo são pesquisadores e estudantes de nível superior, universidades e centros de pesquisa, públicos e privados.

Já o programa Ciência, Tecnologia \& Inovação para a Política Industrial, Tecnológica e de Comércio Exterior - PITCE - tem o objetivo de promover o desenvolvimento científico-tecnológico e inovações voltadas à melhoria da competitividade de produtos e processos de empresas nacionais e à criação e consolidação de nichos de mercado baseados em novas tecnologias, visando à expansão da economia brasileira no mercado internacional. Seu público-alvo são empresas nacionais, de biotecnologia, de nanotecnologia, de química, de materiais, de eletrônica, de energias renováveis, de software, de fármacos, de semicondutores e microeletrônica, prestadoras de serviços tecnológicos, de consultoria tecnológica, atuantes em pesquisa e 
desenvolvimento de produtos e processos em áreas de fronteira tecnológica, comunidade científica e tecnológica.

Tabela 5

Orçamento do CNPq segundo Programas e Ações do PPA 2002-2010 (em milhares de R\$)

\begin{tabular}{cccccccc}
\hline Período & $\begin{array}{c}\text { Formação e } \\
\text { Capacitação de } \\
\text { Recursos } \\
\text { Humanos para } \\
\text { CT\&I }\end{array}$ & $\begin{array}{c}\text { Promoção da } \\
\text { Pesquisa e do } \\
\text { Desenvolvimen } \\
\text { to Científico e } \\
\text { Tecnológico }\end{array}$ & $\begin{array}{c}\text { CT\&l para } \\
\text { Política } \\
\text { Industrial, } \\
\text { Tecnol. e de } \\
\text { Comércio } \\
\text { Exterior }- \\
\text { PITCE }\end{array}$ & $\begin{array}{c}\text { Gestão da } \\
\text { Política de } \\
\text { Ciência, } \\
\text { Tecnolo gia } \\
\text { e Inovação }\end{array}$ & $\begin{array}{c}\text { Ciência, } \\
\text { Tecnologia \& } \\
\text { Inovação } \\
\text { Aplicada aos } \\
\text { Recursos } \\
\text { Naturais }\end{array}$ & $\begin{array}{c}\text { Outras } \\
\text { Ações }\end{array}$ & Total Geral \\
\hline $\mathbf{2 0 0 2}$ & 432.937 & 0 & 0 & 1.584 & 0 & 269.247 & 703.768 \\
$\mathbf{2 0 0 3}$ & 461.338 & 0 & 0 & 4.616 & 0 & 410.693 & 876.647 \\
$\mathbf{2 0 0 4}$ & 545.151 & 124.366 & 0 & 4.473 & 0 & 272.622 & 946.612 \\
$\mathbf{2 0 0 5}$ & 598.591 & 105.456 & 0 & 4.746 & 0 & 316.981 & 1.025 .774 \\
$\mathbf{2 0 0 6}$ & 626.994 & 128.599 & 154.933 & 5.632 & 35.991 & 67.732 & 1.019 .881 \\
$\mathbf{2 0 0 7}$ & 657.062 & 147.075 & 177.368 & 5.958 & 41.877 & 173.950 & 1.203 .290 \\
$\mathbf{2 0 0 8}$ & 588.700 & 144.642 & 419.042 & 4.990 & 32.891 & 233.358 & 1.423 .623 \\
$\mathbf{2 0 0 9}$ & 748.121 & 162.406 & 405.673 & 4.388 & 35.644 & 310.163 & 1.666 .395 \\
$\mathbf{2 0 1 0}$ & 864.722 & 162.252 & 630.164 & 2.192 & 27.193 & 260.966 & 1.947 .489 \\
\hline
\end{tabular}

Nota Fonte: Adaptado de Conselho Nacional de Desenvolvimento Científico e Tecnológico. (2010). Relatório de Gestão 2010. Recuperado em 27 dezembro, 2012, de http://www.cnpq.br/documents/10157/45688/relatorio_gestao_2010.pdf.

Dentre as ações deste programa, o CNPq executa somente a ação Fomento a Projetos de Pesquisa e Desenvolvimento Tecnológico. Entretanto, em parceria com o MCTI, executa às seguintes ações: apoio às redes de nanotecnologia; apoio à PD\&l em biotecnologia; apoio ao desenvolvimento da tecnologia industrial básica para a inovação e competitividade; promoção do desenvolvimento da indústria de projeto e fabricação de componentes semicondutores; apoio à pesquisa de resíduos e contaminantes; fomento a projetos de P\&D em nanotecnologia.

Com relação à Promoção da Pesquisa e do Desenvolvimento Científico e Tecnológico, este programa tem como objetivo ampliar e ajustar a base técnico-científica do país às necessidades de conhecimento e de serviços em ciência e tecnologia, sendo seu público-alvo formado por instituições de pesquisa, universidades e empresas nacionais. Neste programa, o CNPq executa as seguintes ações: implantação de institutos de pesquisa padrão internacional - Institutos do Milênio, fomento à pesquisa fundamental, difusão da produção científica nacional, apoio a núcleos de excelência - PRONEX. As atividades realizadas em parceria com o MCTI e FNDCT foram relacionadas às ações: pesquisa e desenvolvimento no Instituto Nacional do Semi-Árido - INSA; apoio às entidades para promoção de eventos científicos e tecnológicos; fomento a projetos institucionais de ciência e tecnologia e fomento a projetos de fortalecimento da capacidade científica e tecnológica. Além disso, também realiza ações financiadas pelo CT-INFRA e em parceria com o Ministério da Saúde. É, ainda, no âmbito deste programa que o CNPq financia grupos de excelência em todo o país, em parceria com Fundações Estaduais de Amparo à Pesquisa e, também, apoia grupos emergentes, visando contribuir para que se consolidem e alcancem patamares crescentes de excelência.

O programa Gestão da Política de Ciência, Tecnologia e Inovação possui como objetivo coordenar o planejamento e a formulação de políticas setoriais e a avaliação e controle dos programas na área de Ciência, Tecnologia e Inovação e tem como público-alvo o Governo. Este programa envolve ações voltadas para o Sistema Integrado de Informações em C\&T (Plataforma Lattes), capacitação de servidores púbicos federais em qualificação e requalificação, cooperação internacional em CT\&l e ações executadas em parceria com o MCTI.

Já o programa Ciência, Tecnologia \& Inovação Aplicada aos Recursos Naturais busca ampliar o conhecimento técnico-científico sobre as interações entre a ciência, a natureza e a sociedade, que contribuam para aprofundar o entendimento de aspectos meteorológicos, hidrológicos e ambientais, bem como dos mecanismos determinantes de mudanças climáticas globais, visando à melhoria da qualidade de vida da população. Seu público-alvo envolve a comunidade científica e a sociedade. Neste programa, o CNPq executa as seguintes ações: fomento à pesquisa e ao desenvolvimento sobre a composição e a dinâmica dos ecossistemas brasileiros; e fomento à pesquisa e ao desenvolvimento em ciência e tecnologia do mar.

Com relação à produção tecno-científica, observa-se, na Tabela 6, de acordo com dados do portal do MCTI, a produção técnica (http://www.mct.gov.br/index.php/content/view/5705/Brasil_Producao_tecnica_no_diretorio_dos_grupos_de_pesq uisa_do_Conselho_Nacional_de_Desenvolvimento_Cientifico_e_Tecnolōgico_CNPq.htht, recuperado em 20

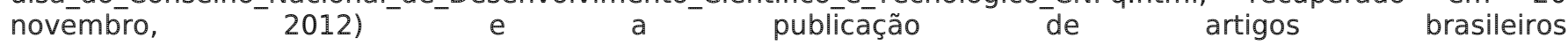
(http://www.mct.gov.br/index.php/content/view/5710.html, recuperado em 28 dezembro, 2012) dos anos de 
2002 a 2010. Os dados da produção técnica foram extraídos do MCTI, Produção técnica no diretório dos grupos de pesquisa do CNPq, considerando-se os softwares com registro ou patente e produtos tecnológicos com registro ou patente. Os dados da publicação foram retirados do Número de artigos brasileiros publicados em periódicos científicos indexados pela Scopus, 2002-2010, disponível pelo MCTI.

\section{Tabela 6}

Produção técnica e publicação brasileiros, 2002-2010

\begin{tabular}{lrc}
\hline Ano & Produção Técnica $^{a}$ & Publicação $^{b}$ \\
\hline $\mathbf{2 0 0 2}$ & 2.363 & 15.763 \\
$\mathbf{2 0 0 3}$ & 2.436 & 17.610 \\
$\mathbf{2 0 0 4}$ & 2.686 & 19.554 \\
$\mathbf{2 0 0 5}$ & 2.884 & 21.858 \\
$\mathbf{2 0 0 6}$ & 2.849 & 27.382 \\
$\mathbf{2 0 0 7}$ & 2.925 & 30.040 \\
$\mathbf{2 0 0 8}$ & 3.027 & 34.582 \\
$\mathbf{2 0 0 9}$ & 3.454 & 39.881 \\
$\mathbf{2 0 1 0}$ & 3.396 & 43.169
\end{tabular}

Nota Fonte: Adaptado de ${ }^{a}$ Ministério da Ciência, Tecnologia e Inovação do Brasil. (2012). Brasil: Produção técnica no diretório dos grupos de pesquisa do Conselho Nacional de Desenvolvimento Científico e Tecnológico (CNPq), 2000-2010. Recuperado em 20 novembro, 2012, de http://www.mct.gov.br/index.php/content/view/5705/Brasil_Producao_tecnica_no_diretorio_dos_grupos_de_pesquisa_do_Conselho_Nacional_d e_Desenvolvimento_Cientifico_e_Tecnologico_CNPq.html

b Adaptado de Ministério da Ciência, Tecnologia e Inovação do Brasil. (2012). Número de artigos brasileiros, da América Latina e do mundo publicados em periódicos científicos indexados pela Thomson/ISI e Scopus, 1996-2011. Recuperado em 28 dezembro, 2012, de http://www.mct.gov.br/index.php/content/view/5710.html.

A partir dos dados das tabelas 5 e 6 realizou-se a análise de correlação, obtendo-se como resultado a Tabela 7. A codificação adotada para as variáveis foi: Formação e Capacitação de Recursos Humanos para CT\&l (x1); Promoção da Pesquisa e do Desenvolvimento Científico e Tecnológico (x2); CT\&l para a Política Industrial, Tecnológica e de Comércio Exterior - PITCE (x3); Gestão da Política de Ciência, Tecnologia e Inovação (x4); Ciência,Tecnologia \& Inovação Aplicada aos Recursos Naturais (x5); Outras Ações (x6) e Total Geral (x7), para variáveis independentes e Publicação (y1) e Produção Técnica (y2) para as variáveis dependentes.

Tabela 7

Resultados da Análise de Correlação Investimentos CNPq x Produção Técnica e Publicação

\begin{tabular}{|c|c|c|c|c|c|c|c|c|c|}
\hline & $\mathrm{X} 1$ & $\mathrm{X} 2$ & $\mathrm{x} 3$ & $\mathrm{X} 4$ & $\mathrm{X5}$ & $\mathrm{X6}$ & $\mathrm{X} 7$ & Y1 & $\mathrm{Y} 2$ \\
\hline $\mathrm{X} 1$ & 1 & & & & & & & & \\
\hline $\mathrm{X} 2$ & 0,8259 & 1 & & & & & & & \\
\hline X3 & 0,8423 & 0,6774 & 1 & & & & & & \\
\hline$X 4$ & $-0,0132$ & 0,3584 & $-0,1748$ & 1 & & & & & \\
\hline$\times 5$ & 0,6511 & 0,7255 & 0,6838 & 0,4030 & 1 & & & & \\
\hline$X 6$ & $-0,2421$ & $-0,4620$ & $-0,1693$ & $-0,3245$ & $-0,6353$ & 1 & & & \\
\hline X7 & 0,9245 & 0,7511 & 0,9580 & $-0,1037$ & 0,6247 & $-0,0448$ & 1 & & \\
\hline Y1 & $0,9185^{*}$ & $0,8076^{*}$ & $0,9616^{*}$ & 0,0163 & $0,7815^{*}$ & $-0,2316$ & $0,9722^{*}$ & 1 & \\
\hline Y2 & $0,7036^{*}$ & $0,7726^{*}$ & $0,7569 *$ & 0,3953 & $0,8794^{*}$ & $-0,2740$ & $0,7723^{*}$ & $0,8518^{*}$ & 1 \\
\hline
\end{tabular}

Fonte: Elaborado pelos autores

*Valores Significativos para $p<0,05$

Com relação ao coeficiente de correlação, segundo Costa (2013), este pode ser avaliado da seguinte forma: existe baixa correlação linear entre 0,0 e 0,4; moderada correlação entre 0,4 e 0,8 e alta correlação acima de 0,8 .

A partir dos dados da Tabela 7, destaca-se que existe forte correlação entre os investimentos nas ações de Formação e Capacitação de Recursos Humanos para CT\&l; CT\&l para Políticas Industriais, Tecnológicas e de Comércio Exterior - PITCE e o investimento total com a publicação de artigos. Existe moderada correlação entre o investimento em Promoção da Pesquisa e do Desenvolvimento Científico e Tecnológico; Ciência, Tecnologia \& Inovação Aplicada aos Recursos Naturais com a publicação de artigos. Com relação aos investimentos na 
Gestão da Política de Ciência, Tecnologia e Inovação nota-se que existe baixíssima correlação e que há baixa correlação negativa com Outras Ações.

No que diz respeito aos investimentos em outras ações, observa-se que a classificação foi realizada de maneira adequada, visto que estes investimentos não apresentaram correspondência com a publicação científica.

No que tange à produção técnica, ressalta-se que esta possui moderada correlação com os investimentos em Formação e Capacitação de Recursos Humanos para CT\&l; Promoção da Pesquisa e do Desenvolvimento Científico e Tecnológico; CT\&l para Políticas Industriais, Tecnológicas e de Comércio Exterior - PITCE e o investimento total e forte correlação com os investimentos em Ciência, Tecnologia \& Inovação Aplicada aos Recursos Naturais.

Assim como na análise da publicação, constata-se que há baixa correlação, inclusive negativa, entre os investimentos em Outras Ações e a produção técnica, corroborando a classificação efetuada. Com relação aos investimentos na Gestão da Política de Ciência, Tecnologia e Inovação verifica-se que existe baixa correlação.

Voltando-se para os investimentos na Gestão da Política de Ciência, Tecnologia e Inovação, este ponto merece destaque visto que houve um aumento do investimento de 2002 até 2007 e um declínio do investimento nos anos de 2008 a 2010. Esse movimento produziu correlações baixas com as variáveis de resultado, talvez por se tratar de uma ação de formação de gestores e reforço dos órgãos que fazem a administração da CT\&l, esta possivelmente foi programada em etapas com investimentos iniciais altos e em seguida manutenção com um orçamento menor.

Pode-se destacar também que a ação de Gestão da Política de Ciência, Tecnologia e Inovação, mesmo com baixos índices de correlação, se comparada entre as variáveis de resultados, apresenta maior relação com os pedidos de patente (produção técnica), isso se justifica pelo fato do esforço em transformar a ciência em inovação demandar processos gerenciais.

\section{Conclusões}

Devido à importância da C\&T para o desenvolvimento, os dispêndios dos países e instituições para o tema têm crescido. Neste sentido, o Brasil tem buscado aumentar cada vez mais seus investimentos em C\&T. Entretanto, é necessário acompanhar e analisar os resultados destas ações e do desenvolvimento de políticas de incentivo a C\&T.

Com base nos resultados, sugerem-se indícios de que o aumento do investimento do Governo Brasileiro em Ciência e Tecnologia tem refletido no aumento da produção técnica e na publicação de artigos. Em relação à publicação de artigos, observa-se que esta possui correlação com cinco de um total de sete itens dos investimentos analisados e baixa correlação com dois itens. No que tange à produção técnica, também há correlação com cinco dos sete itens.

Destacam-se os seguintes programas: (a) Investimento em Ciência, Tecnologia e Inovação aplicada aos recursos naturais, o qual possui o maior índice de correlação com a produção técnica, e o programa (b) CT\&l para Políticas Industriais, Tecnológicas e de Comércio Exterior, maior índice de correlação com a publicação. 0 investimento total, que compreendeu a soma de todos os recursos associados à pesquisa, apresentou alta correlação com a publicação.

Observa-se o aumento substancial do dispêndio no programa CT\&l para Políticas Industriais, Tecnológicas e de Comércio Exterior. Isto indica o crescimento da importância que os investimentos em CT\&l vêm assumindo para a competitividade das empresas e do país. Nota-se, também, conforme destacado pelo Centro de Gestão e Estudos Estratégicos (2010), que o trabalho de institutos privados em conjunto com universidades, centros de pesquisa de empresas privadas e públicas, fundações e outros organismos de P\&D e de apoio tem crescido e auxiliado no desenvolvimento de novos conhecimentos e na produção técnico-científica no Brasil.

Os resultados do estudo apontam evidências de que universidades, instituições de pesquisa e organizações de C\&T quando dos aportes financeiros e de qualificação de pessoal têm respondido de forma positiva para a criação de um ambiente de inovação que tem apresentado crescimento da ciência, tecnologia e inovação, corroborando as ideias de Zawislak et al (2008), isso sugere que há indícios do desenvolvimento tecnológico do País.

Pode-se considerar que há perspectivas promissoras para o país, pois se percebeu que também há correlação positiva entre a publicação científica e produção técnica, reforçando a ligação entre ciência e tecnologia melhorando Pesquisa \& Desenvolvimento aplicados, conforme sugerido por Klevorick et al (1995).

Os resultados puderam também apontar que o país tem se enquadrado nas modernas sociedades, pois já se percebe que a complexidade tecnológica alcançou estágios nas quais é indispensável o investimento em inovação, verificado pelos sucessivos aumentos nos investimentos em CT\&l, pelo menos no que se refere às etapas de pesquisa fundamental e pesquisa aplicada, confirmando parte das etapas do processo de inovação abordado por Zawislak (1994). 
Ainda que os pedidos brasileiros de patentes correspondam a uma pequena fração do total mundial, percebe-se o crescimento da importância da propriedade intelectual para o governo, as empresas e instituições envolvidas com inovação. São exemplos desses esforços de incentivo a geração de patente as políticas públicas implementadas nos últimos anos, incluindo a Política Industrial, Tecnológica e de Comércio Exterior (PITCE), a Lei da Inovação e a Lei do Bem, as linhas de crédito e fomento disponibilizadas pelo Banco Nacional de Desenvolvimento Econômico e Social (BNDES) e pelas agências de fomento, entre outras iniciativas nos âmbitos federal e estadual. São também exemplos a instalação de incubadoras de empresas nas universidades e a criação de Núcleos de Inovação Tecnológica (NIT) ou agências de inovação nos institutos de ciência e tecnologia (ICT), como previsto na Lei de Inovação, conforme destacado por Takaki, Camargo, Mendes e Sennes (2008).

O estudo apresenta algumas limitações que merecem reflexão. A primeira trata do fato da análise ter sido restrita aos investimentos realizados pelo $\mathrm{CNPq}$, não se levando em consideração os investimentos efetuados por outras instituições de fomento à Ciência e Tecnologia. Outra limitação refere-se ao fato de que o estudo restringiu-se a produção relacionada apenas à publicação e o número de patentes.

A análise da relação com valores globais, não pode ser tratada como definitiva, principalmente porque nos últimos dez anos existiram ações que também foram importantes para o aumento da produção em C\&T no país, como as mudanças nas regras de produtividade nas áreas do conhecimento estabelecidas pela CAPES, o aumento no número de programas de pós-graduação e de doutores.

A temporalidade dos dados também merece considerações tendo em vista que os dados foram coletados a partir de um período anterior à realização da pesquisa, analisando-se os anos de 2002 a 2010 . Uma questão que merece destaque é o fato de que os efeitos dos investimentos considerados podem ocorrer no prazo posterior ao período analisado.

Quanto às contribuições, o estudo apresenta algumas que devem ser mencionadas. Para a academia, destaca-se que ao atingir o objetivo proposto, incorreu-se no aprofundamento das relações entre investimento e produção técnico-científica, propiciando subsídios para a área de Gestão e Estratégia. Além disso, também permitiu a aplicação e difusão da análise de correlação, indicando uma técnica associada à apreciação de quanto uma variável interfere no resultado de outra. O estudo possibilita também uma agenda de pesquisa para continuação das investigações realizadas. Na prática, os resultados podem ser utilizados como forma de auxiliar a elaboração e o desenvolvimento de políticas e programas, avaliar a distribuição de recursos e incentivar a produção técnico-científica, contribuindo para um melhor direcionamento de esforços e investimentos.

Reconhecendo que o estudo não analisou a forma como a produção em CT\&l está relacionada às fontes motivadoras para inovação, mas com estímulo às ideias de Nemet (2009), sugere-se que seja verificado se os resultados aqui produzidos estão de acordo com as necessidades explícitas dos consumidores (demand-pull) ou segundo as oportunidades geradas a partir dos avanços da ciência e da tecnologia (technology push), isto se caracteriza como proposições para novos estudos.

\section{Referências}

Alencar, E. (2004). Metodologia Científica e elaboração de monografia. Lavras: UFLA/FAEPE.

Arcuri, R. B. (2010). Desafios institucionais para a consolidacao do Sistema Nacional de Ciencia, Tecnologia e Inovação. Parcerias Estratégicas, v. 15, 31, 33-40.

Asheim, B. T., \& Isaksen, A. (2002). Regional innovation systems: the integration of local 'sticky' and global 'ubiquitous' knowledge. The Journal of Technology Transfer, 27(1), 77-86.

Birkinshaw, J., Hamel, G., \& Mol, M.J. (2008). Management innovation. Academy of Management Review, 33 (4), 825-845.

Brandão, S. M., \& Bruno-Faria, M. F. (2013). Inovação no setor público: análise da produção científica em periódicos nacionais e internacionais da área de administração. Revista de Administração Pública, 47(1), 227248. Recuperado em 5 maio, 2013, de http://www.scielo.br/scielo.php?pid=\$0034-

$76122013000100010 \&$ script=sci_arttext\&tlng $=$ pt.

Centro de gestão e estudos estratégicos. (2010). Modelos institucionais das organizações de pesquisa: série documentos técnicos. Brasília: Centro de Gestão e Estudos Estratégicos.

Conselho Nacional de Desenvolvimento Científico e Tecnológico. (2010). Relatório de Gestão 2010. Recuperado em 27 dezembro, 2012, de http://www.cnpq.br/documents/10157/45688/relatorio_gestao_2010.pdf.

Cooke, P. (2003). Regional Innovation and Learning Systems, Cluters, and Local and Global Value Chains. In: BROCKER, J. (eds). Innovation Clusters and Interregional Competiton. USA: Springer Verlag.

Costa, S. F. (2013). Introdução ilustrada a estatística. São Paulo: Harbra.

Dosi, G. (1988). Sources, procedures, and microeconomic effects of innovation. Journal of Economic Literature, 26 (3), 1120-1171. 
Etzkowitz, H. (2009). Hélice tríplice: universidade-indústria-governo: inovação em ação. Porto Alegre: EDIPUCRS. Figueiredo, P. N. (2004). Aprendizagem tecnológica e inovação industrial em economias emergentes: uma breve contribuição para o desenho e implementação de estudos empíricos e estratégias no Brasil. Revista Brasileira de Inovação, 3 (2), 323 - 361. Recuperado em 12 janeiro, 2013, de https://www.ige.unicamp.br/ojs/index.php/rbi/article/view/275/191.

Garnica, L. A., \& Jugend, D. (2009). Estímulo à inovação em empresas de base tecnológica de pequeno porte: Uma análise da Lei Federal Brasileira de Inovação. Revista da Micro e Pequena Empresa, 3 (1), 82 - 98. Recuperado em 9 dezembro, 2013, de http://www.faccamp.br/ojs/index.php/RMPE/article/view/62/52.

Godinho, M. (2007). Indicadores de C\&T, inovação e conhecimento: Onde estamos? Para onde vamos? Análise Social, vol. XLII (182), 239-274.

Hicks, J.R. (1932). The Theory of Wages. London: Macmillan.

Klevorick, A. K., Levin, R. C., Nelson, R. R., \& Winter, S. G. (1995). On the sources and significance of interindustry differences in technological opportunities. Research Policy, 24, 185-205.

Lei n 11.196/2005, de 21 de novembro de 2005. (2005). Dispõe sobre incentivos fiscais para a inovação tecnológica. Brasília, DF. Recuperado em 20 setembro, 2012, de http://www.planalto.gov.br/ccivil_03/_ato20042006/2005/lei/l11196.htm.

Lei n 10.973, de 2 de dezembro de 2004. (2004). Dispõe sobre incentivos à inovação e à pesquisa científica e tecnológica no ambiente produtivo e dá outras providências. Brasília, DF. Recuperado em 20 setembro, 2012 , de http://www.planalto.gov.br/ccivil_03/_ato2004-2006/2004/lei/l10.973.htm.

Lemos, M. B., \& De Negri, J.A. (2010). FNDCT, Sistema Nacional de Inovação e a presença das empresas. Parcerias Estratégicas, 15, (31), 187 - 243.

Lundvall, B. A. (1992). National innovation systems: towards a theory of innovation and interactive learning. London: Pinter.

Malerba, F. (2002). Sectoral systems of innovation and production. Research Policy, 31, $247-264$.

Ministério da Ciência, Tecnologia e Inovação do Brasil. (2011). Rede de indicadores estaduais de C\&T. Brasília: MCTI.

Mowery, D., \& Rosenberg, N. (1979). The influence of market demand upon innovation: a critical review of some recent empirical studies. Research Policy, 8 (2), 102-153.

Nelson, R. R. (1993). National Innovation Systems. A Comparative Analysis. New York: Oxford University.

Nemet, G. F. (2009). Demand-pull, technology-push, and government-led incentives for non-incremental technical change. Research Policy, 38, 700-709.

Organisation for Economic Cooperation and Development (2005). Oslo Manual. Guidelines for Collecting and Interpreting Innovation Data (3rd ed.). Paris: OECD.

Organisation for Economic Cooperation and Development. (1997). Proposed Guidelines for Collecting and Interpreting Technological Innovation Data - Oslo Manual. The Measurement of Scientific and Technical Activities Series. Paris: OCDE/Eurostat.

Organisation for Economic Cooperation and Development. (2002). Frascati Manual: Proposed Standard Practice for Surveys on Research and Experimental Development. Paris: OECD.

Organisation for Economic Cooperation and Development. (2009). Patent Statistics Manual, 2a edição. Paris: OECD.

Pacheco, E. R. M.(210). Mapeamento do fomento à inovação tecnológica no Brasil. Dissertação de Mestrado, Centro Federal de Educaçao Tecnológica Celso Suckow da Fonseca, Rio de Janeiro, RJ, Brasil.

Pereira, J. A., \& Reinert, M. (2013). A influência das redes sociais na Inovação: um estudo de caso em uma incubada do Centro Incubador Tecnológico - CIT/FUNDETEC. Revista Eletrônica de Ciência Administrativa (RECADM), 12 (2), 6-21. Recuperado em 2 setembro, 2013, de http://revistas.facecla.com.br/index.php/recadm/article/view/1520

Quintella, R. H., Freitas, E. J. S. M., Ventura, A. C., Santos, M. A., Melo, D. R. A., Motta, G. S., \& Jucá, S. (2012). Scientific Knowledge Networks in Peripheral Regions and Local Innovation Systems: The Case of Chemistry in the State of Bahia. Journal of Technology Management \& Innovation, 7 (1), 87-103.

Rede Iberoamericana de Indicadores de Ciencia e Tecnologia. (2001). Manual de bogotá. Normalización de Indicadores de Innovación Tecnológica en América Latina y el Caribe. Bogotá: RICYT.

Rede Iberoamericana de Indicadores de Ciencia e Tecnologia. (2007). Manual de Santiago. Manual de indicadores de internacionalización de la ciencia y la tecnología. Buenos Aires: RICYT.

Rezende, S. M. (2011). A evolução da política de C\&T no Brasil. In: Silva, F. C. T., Dias, J. L. M., Rezende, S.M., Longo, W. P., Derenusson, M. S., \& Fernandes, L. A FINEP no século XXI. Brasil: FINEP. 
Salles-Filho, S., \& Bonacelli, M. B. (2007). Em busca de um novo modelo para as organizações públicas de pesquisa no Brasil. Ciencia e Cultura, vol.59, no.4. São Paulo, 28 - 32.

Schumpeter, J. A. (1961). Capitalismo, Socialismo e Democracia. Editado por George Allen e Unwin Ltd. Tradução de Ruy Jungmann. Rio de Janeiro: Editora Fundo de Cultura.

Schumpeter, J. A. (2002). Economic theory and entrepreneurial history. Revista Brasileira de Inovação, 1 (1), 128-133.

Takaki, A., Camargo, H., Mendes, R., \& Sennes, R. (2008). Propriedade intelectual e inovação: uma análise de dez instituições brasileiras. Parcerias estratégicas, n.26, 179 - 224.

Tigre, P. B. (1998) Inovação e teorias da firma em três paradigmas. Revista de Economia Contemporânea, 3,66 - 111. Recuperado em 7 outubro, 2012, de http://www.ie.ufrj.br/oldroot/hpp/intranet/pdfs/inovacao_e_teorias_da_firma_em_tres_paradigmaspaulotigre.pdf. Tigre, P. B. (2006). Gestão da Inovação: A economia da tecnologia no Brasil. Rio de Janeiro: Elservier.

Vergara, S.C. (2000). Projetos e relatórios de pesquisa em administração. São Paulo: Atlas.

Vieira, M. M. F. (2004). Por uma boa pesquisa (qualitativa) em Administração. In: Vieira, M. M. F., \& Zouain, D. M. Pesquisa qualitativa em administração. Rio de Janeiro: FGV Editora.

Zawislak, P. (1994). Texto Didático no. 2. A Relação entre conhecimento e desenvolvimento. Porto Alegre: NITEC/PPGA/UFRGS.

Zawislak, P., Borges, M., Wegner, D., Santos, A., \& Castro, C. (2008). Towards the Innovation Function. Journal of Technology Management \& Innovation. 3 (4), 17 - 30. Retrieved September 5, 2012, from

http://www.scielo.cl/scielo.php?pid=\$0718-27242008000200002\&script=sci_arttext 